\title{
An Analysis of Job Satisfaction Level of Faculty Members at the University of Sindh
}

\author{
Shamail Shah and Tariq Jalees \\ SZABIST \\ Karachi, Pakistan.
}

\begin{abstract}
:
The focus of the study is to ascertain the overall satisfaction level of the faculty members at the University of Sindh. Based on literature surveys five different predictor variables were identified: the job, supervisors, promotion, pay, and coworkers. A theoretical framework was developed that was inclusive of all the required dependent and independent variables. Eight different hypotheses were developed for testing. Data for testing the hypothesis was collected through a closed ended questionnaire based on the Likert scale. The questionnaires administered were based on 27 items. Seven items were related to personal data, and the rest 20 were related to measuring the overall satisfaction level. The appropriate sample size was 40. However, as there were 44 departments, therefore, stratified proportionate and non-proportionate sampling techniques were used, which increased the sample size to 105. Of the 105 samples 100 samples were valid.
\end{abstract}

Eight hypotheses were formulated and tested though ANOVA, Z test and correlation techniques. The overall satisfaction level was 4.7 on a scale of (1-7). Of the eight hypothesis, five were substantiated and three were rejected.

\section{INTRODUCTION}

Job satisfaction in organizations has been the focus of many research studies because of its importance in measuring employee commitment level, organizational turnover and absenteeism etc [1]. Organizations want their employees to be satisfied, so that they could become more productive and efficient. Public sector employees are comparatively paid less than the private sector employees. The promotional policies in the public sector are seniority based instead of performance and ability. Therefore, the satisfaction level suffers. However, the subject study is focused on measuring the overall satisfaction level of the faculty members of the University of Sindh, a public sector organization. Dimensions used for measuring the over all satisfaction were work itself, pay, coworkers, boss and promotions etc[2] The study also addressed the relationship between demographics and the overall satisfaction level of the faculty members of the said organization.

Recommendations were related to the dimensions used for measuring the overall satisfaction level.

\section{THE UNIVERSITY OF SINDH: BACKGROUND}

The University of Sindh was founded in 1947 under the Sindh Act No. XVIII "An act to establish \& incorporate a University in the province of Sindh". It is the second largest teaching \& research university of Pakistan, housed in 25 modern buildings on an area of 2000 acres. The university has two campuses, one in the city and the other in Jamshoro. The city campus houses "the faculty of education". The campus at Jamshoro houses 40 teaching departments working under 6 faculties. These are as under:

- Faculty of Arts

- Faculty of Commerce \& Business Administration

- Faculty of Education

- Faculty of Islamic Studies

- Faculty of Natural Sciences

- Faculty of Social Sciences.

The University of Sindh offers degree programs at both undergraduate and graduate levels in the disciplines of the liberal arts, teacher education, sciences, management, and technologies [3]

\section{PROBLEM STATEMENT}

Two problem statements have been identified. What is the influence of the dimensions such as work, coworkers, pay, supervisor and future prospects on the satisfactory level of individuals? What is the impact of demographics on the overall satisfaction level?

\section{THEORETICAL FRAMEWORK}

The dependant variable "satisfaction level" is the variable of primary interest. Five commonly used predictors such as "work", "supervisor", "pay", "promotion" and "coworkers" have measured this dependent variable. Demographics such as age, gender, experience and department, exposure to different culture (foreign qualification) etc., always have varying impact on the overall satisfaction level and have been used invariably by all the researchers to measure the impact on the variable of primary concern. [4].

\section{HYPOTHESES}

Based on the theoretical framework, literature survey and problem statement the following eight hypotheses statements were developed [4]. 
1. The over all satisfaction level of the faculty members is high (5) on the scale of (1-7).

2. There is a relationship between the age and the satisfaction level of the faculty members.

3. There is a relationship between the education level and the satisfaction level of the faculty members.

4. The satisfaction level of the local graduates will be higher than the foreign graduates.

5. There is a relationship between the numbers of years in the organization and the satisfaction level of the faculty members.

6. The satisfaction level of the male will be higher than the female faculty members.

7. There is a significant difference between the dimensions used for measuring the overall satisfaction level.

8. There is significant difference between the satisfaction levels of the faculty members working in different faculty.

\section{METHODOLOGY:}

\section{a) Population and Sample Size:}

The population of the study comprised of the faculty members of the University of Sindh. The approximate size of the population was about 400 faculty members. Based on a pilot survey it was ascertained that about 40-sample size would be appropriate, if the samples were to be drawn on simple random. However, due to in-practicability of the same and to have an appropriate representation about $20 \%$ samples were conveniently drawn from each department, and a higher percentage from the smaller departments. This increased the sample size to 105. Of this total, 5 questionnaires were incomplete and thus were discarded.

\section{b) Data Collection Method:}

The closed-ended questionnaires were handed to the faculty members directly in some cases, and the rest through the head of the departments, which were to be collected in a week. However, contrary to the initial estimates, it took more than five weeks for collection of the filled-out questionnaires

\section{SAMPLE CHARACTERISTICS:}

Of the hundred samples, $67 \%$ of the respondents were male and the rest $33 \%$ were females. About $28 \%$ of the respondents were of the age group 25-35, another $28 \%$ were in the age group $35-45$ and $31 \%$ were in the age group $45-55$ the rest $12 \%$ were in the age group of 55 and over. In terms of education, $43 \%$ respondents had Masters level of education and $30 \%$ had $\mathrm{PhD}$. In terms of experience, more than $41 \%$ have been associated with the institution for more than 16 years.

\section{VARIABLES AND MEASURES}

The questionnaire administered for the study was based on 27 items. Of these seven questions were related to personal information: Age, education level, job level, foreign qualification, number of years in the organization, any other source of income, gender, and marital status.

The overall satisfaction levels of the faculty members were measured through the five dimensions based on the likert scale. In each dimensions there were about two negative questions. These negative questions were converted to positive questions before tabulation. The five dimensions used for the measuring the over all satisfaction levels were:

a) Job: The job itself is the most important predictor for the job satisfaction. The sub-dimensions such as accomplishment at job, respect earned due to work, frustration and tiredness at job were used for this dimensions. [4]

b) Supervisor: The second dimension used for measuring the over all satisfaction level was the attitude of the supervisors. This relationship was measured by parameters such as supervisor's willingness to take advice, supervisor's availability, effort required to please the supervisor and supervisor's degree of appreciating good work. [4]

c) Coworkers: "Coworkers" is also an important predictor for measuring the overall job satisfaction. The subdimension used in this case was whether the coworkers are stimulant, and loyal, or they have narrow interest and are difficult to get along with. [4]

d) Pay: Though not considered as a vital dimension for measuring the overall satisfaction level, however, it is still considered as an important dimension in developing countries due to high polarization in public and private sectors remuneration. The parameters used to measure the pay were its adequateness; are the respondents overly paid, barely meeting expenses, or less than their expectations. [5]

e) Promotion: is also considered as a multidimensional parameter for measuring the over all satisfaction level 5]. The promotional aspect was measured through parameters such as opportunities for advancement based on ability, fairness and future prospects at the job [6]

\section{DATA ANALYSIS METHODS:}

The data were mostly measured through measure of central tendencies including mean, mode, median etc. The hypothesis developed were tested through, Ztest, simple ANOVA and correlation analysis. 


\section{SURVEY FINDINGS:}

The survey findings were analyzed linearly and crosssectionally in order to have a better comprehension and understanding of the relationship between dependent and independent variables, which are discussed below:

\section{a) Measure of Central Tendencies:}

The data on satisfaction level was based on rating scale, therefore the results were analyzed based on mean, mode and standard deviation etc. The results are summarized below:

Table 1: Measure Of Central Tendencies

\begin{tabular}{|c|c|c|c|c|c|c|}
\hline & \multirow[b]{2}{*}{ Work } & \multirow{2}{*}{$\begin{array}{l}\text { Super- } \\
\text { visor }\end{array}$} & \multirow{2}{*}{$\begin{array}{l}\text { Co- } \\
\text { worker }\end{array}$} & \multirow[t]{2}{*}{ Pay } & \multirow{2}{*}{$\begin{array}{l}\text { Pro- } \\
\text { motion }\end{array}$} & Over \\
\hline & & & & & & all \\
\hline Mean & 5.61 & 4.87 & 4.49 & 3.81 & 4.73 & 4.70 \\
\hline Mode & 5.25 & 5 & 4.75 & 4.25 & 4.75 & 4.95 \\
\hline Median & 5.63 & 5.00 & 4.50 & 3.75 & 4.75 & 4.85 \\
\hline Skewness & .339 & .134 & $(.20)$ & $(.323)$ & $(.157)$ & $(0.1332)$ \\
\hline Kurtosis & 2.55 & 15.85 & 0.43 & 0.08 & $(0.53)$ & 0.40 \\
\hline Std.Dev & 1.06 & 1.56 & 1.30 & 1.36 & 1.27 & 0.80 \\
\hline
\end{tabular}

The overall satisfaction level measured on the scale of 1 to 7 was 4.70. It may be pointed out that the faculty members appeared to be most happy with the work itself with a mean of 5.61 and the least happy with the remuneration with a mean of 3.81. This result of least satisfaction on "pay" was expected. The University of Sindh is a Public Sector institution, and there is a huge polarization between the remuneration of the public sector and the private sector institutions. Interestingly, the standard deviation on pay was quite high. The reasons for such a deviation is that the pay scales at different levels do not increase proportionally. The respondent at the induction and intermediately level were found to be less satisfied with pay as compared to the respondent at the higher level

\section{b) Pearson Correlation:}

Pearson correlation matrix was developed in order to determine the correlation between the dimensions used for assessing the over all satisfaction level. The summarized results are presented below:

Table 2: Pearson Correlation Matrix

\begin{tabular}{|l|c|c|c|c|c|c|}
\hline & Work & $\begin{array}{l}\text { Super- } \\
\text { visor }\end{array}$ & $\begin{array}{l}\text { Co- } \\
\text { workers }\end{array}$ & Pay & $\begin{array}{l}\text { Pro- } \\
\text { motion }\end{array}$ & $\begin{array}{l}\text { Over } \\
\text { all }\end{array}$ \\
\hline Work & 1 & & & & & \\
\hline Supervisor & 0.262 & 1 & & & & \\
\hline Coworker & 0.182 & 0.459 & 1 & & & \\
\hline Pay & 0.113 & 0.232 & 0.063 & 1 & & \\
\hline Promotion & 0.285 & 0.110 & 0.350 & 0.144 & 1 & \\
\hline Overall & 0.557 & 0.688 & 0.688 & 0.485 & 0.602 & 1 \\
\hline
\end{tabular}

It may be noted that the respondents' opinion on the work (independently) was highest with an average mean of 5.6 compared to the over all satisfaction level of 4.7, as earlier discussed in Table-1. However, the correlation of the same with the other independent variable further reinforces what the respondents opined. The correlation of the work was highest with the promotion followed by supervisors and the lowest with the pay.

Therefore, it can be inferred that the respondents' perception on the work could be further improved if the institution develops a well-structured promotional policy based on ability and qualification and not on seniority as the public sector institutions conventionally practice. Respondents' average opinion on the pay was the lowest with the mean of the 3.8 (refer table-1), but, it has the least correlation with work as compared to the other variables.

Similarly, the correlation between the supervisor and coworkers was highest followed by correlation between supervisor, pay and supervisor, and promotion.

The correlation between pay and promotion was lowest indicating that promotion does not give substantial benefit in monetary terms compared to non-monetary benefit such as authority and status.

\section{CONCLUSION}

The overall satisfaction level of the employees was 4.7. Comparatively, the satisfaction levels were in the range of 3.81 to 5.61 , for pay and work respectively.

The correlation between all the selected dimensions was also carried out based on Pearson correlation matrix. The highest correlation was found between promotion and coworkers. The least correlation was found between promotion and supervision.

Eight different hypotheses were developed and tested of this total 5 hypotheses were substantiated and 3 were rejected as illustrated below:

Hypothesis 1 was that the overall satisfaction level of the faculty members was 5 on a scale of 1-7. This hypothesis was accepted as the calculated $\mathrm{Z}$ value $(-0.312)$ fell in the non-critical region.

Hypothesis 2 was that there is a relationship between the satisfaction level and age. The correlation was 0.916. At $95 \%$ confidence level and 29 degree of freedom, the correlation coefficient must be at least 0.313 , which it was. Therefore, the null hypothesis was accepted. This findings were similar to an earlier research in which it was found that "Job satisfaction is lowest when people are in their 20s and 30 s this is the period when people struggle to balance work with their family commitments and highest among staff in their 50s and 60s"'[6]. 
Hypothesis 3 was that there is a relationship between education level and satisfaction level of the faculty members. The correlation coefficient to be statistically significant must be at least 0.198 , as the calculated correlation of 0.159 was lesser, therefore, the null hypothesis was rejected.

Hypothesis 4 was that the satisfaction level of the local graduates was higher than the foreign graduates. At $95 \%$ confidence level, the critical region is (-1.645) as compared to calculated $\mathrm{Z}$ value of 2.8 . Therefore, the null hypothesis was accepted.

The foreign graduates are exposed to different culture that broaden their horizon and perception, therefore, it was expected that their satisfaction level would be lower than the local graduates.

Hypotheses 5 was that there was a relationship between experience/ number of years spent in the organization and satisfaction level of the faculty members. This hypothesis was also substantiated. To be statistically significant calculated correlation must be at least 0.304 , which was although, the relationship was negative as the calculated correlation was (-0.322). Working in the same environment over a period of time leads to dissatisfaction and results in the turnover of the employees. However, due to fewer opportunities in developing countries, generally, the employees do not switch jobs because of dissatisfaction. This is truer for those who are associated with public sector institutions, as it provides them with a sense of security.

Hypothesis 6 was that the satisfaction level of the male members was higher than the female members. This hypothesis was substantiated as at $95 \%$ confidence level the $\mathrm{Z}$ value fell in the non-critical region. This finding was contrary to the findings to the research on the analysis of British researchers on Job satisfaction. The analysis of British data on job satisfaction show that women are happier at work than men: " $22 \%$ of female workers declared themselves as completely satisfied at work as against only $13 \%$ of male workers" [7].

Hypothesis 7 was that there was a significant difference between the dimensions used for measuring the overall satisfaction level. This hypothesis was rejected since there was no significant difference between the dimensions. Therefore, further analysis for measuring the significant difference between the dimensions independently and in combination was not carried out.

Hypothesis 8 was that there was a significant diffe rence between the satisfaction level of faculty members working in different departments. This hypothesis was also rejected and there was no significant difference between the satisfaction levels of the faculty members of different faculty. Since there was not much significant difference, therefore further analysis was not carried out.

\section{RECOMMENDATIONS:}

The over all satisfaction level could be further improved by addressing those dimensions where the satisfaction levels were found to be below the overall satisfaction level.

The lowest satisfaction level of respondents was in the dimension of pay. This problem of dissatisfaction with remuneration has become more significant due to the commissioning of private universities where the remuneration rate of the employees is much higher than the public sector universities.

a) The increase in pay is beyond the authority of the university management. However, the university can allow its faculty members to teach in the private sector without any conditions. Moreover, it may also encourage the faculty member to undertake consultancy assignments which would lead to job enrichment.

b) The faculty members were not happy with their immediate bosses. The procedure of appointment of head of department is based only on seniority. This criterion must be modified. Appropriate weight must be given to seniority, performance, leadership and interpersonal relations with coworkers.

c) For leadership quality and interpersonal relations, the institution must carry out the required test. Moreover, after promotions the promotees must go through rigorous training on leadership, motivation, and human relation.

There was a major dissatisfaction expressed with the dimension of promotion. The promotion becomes effectives on the availability of vacant post. This stereotype system must be restructured in order to accommodate qualified people waiting for promotion. More posts should be created to facilitate people who qualify for the same.

d) There was low satisfaction amongst the coworkers. The faculty members were a bit cautious while answering questions concerning coworkers. Due to defective system of promotion and distribution of rewards various pressure groups have emerged that have contributed towards an adverse environment of mistrust and resentment among the faculty members.

The university should develop a transparent system of promotions and reward distribution Faculty members' problems should be addressed individually so that everyone can get their due share of rights. This will make the pressure groups ineffective. 


\section{References:}

[1] Stephen .P. Robbins, Organizational Behavior concepts controversies and applications, (prentice hall International edition $8^{\text {th }}$ edition 1998).

[2] P.C Smith, L..M.Kendall and Chulin, The measurement of satisfaction in work and retirement (Skokie 11 Rand McNally, 1969)

[3] Sindh University Catalogue 2004. Sindh University Press.

[4] Uma Sekran, Research Methods of Business A skill building approach (John Wiley \& Sons, Inc)
[5] Stephen P Robinson, Organization Behavior concepts controversies and applications, (Prentice Hall $8^{\text {th }}$ Edition 1998)

[6] Job Satisfaction among Community College Faculty Publication date:1998-06-00 Source: Eric Clearing House for Junior Colleges, Los Angeles,

[7] Anna Sanz De Galdano Women are happier at work than men. (published for ISER, Institute of Social Science and Economic Research, University of Essex, UK 2001- this paper was presented at the BHPS 2001 conference at the institute of Social Science and Economic Research on Friday 6 July. 